\title{
Coping with Chronic Social Stress in Mice: Hypothalamic-Pituitary-Adrenal/ Sympathetic-Adrenal-Medullary Axis Activity, Behavioral Changes and Effects of Antalarmin Treatment: Implications for the Study of Stress-Related Psychopathologies
}

\author{
Joana Pérez-Tejada Amaia Arregi Eneritz Gómez-Lázaro Oscar Vegas \\ Arantza Azpiroz Larraitz Garmendia \\ Department of Basic Psychological Processes and their Development, Basque Country University, \\ San Sebastián, Spain
}

\begin{abstract}
Key Words
Chronic social stress - Corticotrophin-releasing hormone . Corticosterone - Catecholamine - Catecholamine enzyme synthesis · Antalarmin - Coping · Mood disorders · Mice
\end{abstract}

\begin{abstract}
The aim of this study was to analyze the individual differences that lead to the development of psychopathological changes in response to chronic social stress. We also assessed the ability of an antagonist of the corticotrophin-releasing hormone $(\mathrm{CRH})$ receptors to reverse the effects of stress. Male adult mice were exposed to repeated defeat experiences for 21 days using a sensorial contact model. After 18 days of defeat, two groups of subjects were established (active and passive), according to their behaviors during social confrontation. Antalarmin treatment was given for 4 and 6 days. The results corroborated previous data indicating that subjects who adopted a passive coping strategy had higher corticosterone levels after 21 days of defeat and decreased resting levels 3 days later. Moreover, they showed higher resting ex-
\end{abstract}

pression levels of hypothalamic $\mathrm{CRH}$ than their active counterparts. On day 24 , the experimental animals were subjected to another social defeat to determine whether the stress response remained. The increase in corticosterone and hypothalamic CRH levels was similar for all of the stressed subjects, but the passive subjects also had a greater $\mathrm{CRH}$ response in the amygdala. Passive subjects had decreased levels of adrenal dopamine $\beta$-hydroxylase, tyrosine hydroxylase and plasma adrenaline compared to the active subjects, and lower plasma noradrenaline levels than manipulated controls. The passive profile of physiological changes in both the hypothalamic-pituitary-adrenal and sympathetic-adrenal-medullary (SAM) axes has been associated with changes related to mood disorders, such as posttraumatic stress disorder and depression. The active coping profile is characterized by similar corticosterone resting levels to controls and increased SAM activity. Both profiles showed alterations in the novel palatable and forced swimming tests, with the passive profile being the most vulnerable to the effects of stress in this last test. Pharmacological treatment with antalarmin failed to reverse the effects of stress.

Copyright $\odot 2013$ S. Karger AG, Basel

\section{KARGER}

E-Mail karger@karger.com

www.karger.com/nen
(C) 2013 S. Karger AG, Basel

0028-3835/13/0981-0073\$38.00/0
L. Garmendia

Department of Basic Psychological Processes and Their Development Basque Country University, Avda, Tolosa 70

ES-20018 San Sebastián (Spain)

E-Mail l.garmendia@ehu.es 


\section{Introduction}

Chronic social stress is one of the main factors responsible for the development of a number of psychopathological disorders in humans [1]. However, individual differences exist in the way people cope with stress, and these differences may result in different physiological patterns in systems such as the hypothalamic-pituitary-adrenal (HPA) and sympathetic-adrenal-medullary (SAM) axes, which play key roles in the stress response. Many studies have demonstrated the individual variability in the stress response of the HPA axis [2-5], but only a few focus on the SAM axis $[3,6]$.

Previous reports indicate that subjects may differ in their HPA response to stress, showing both an excess and a deficit of activity, which give rise to the development of different pathologies [7]. In particular, patients suffering from depression have hypercortisolism and reduced inhibitory feedback $[8,9]$. However, in cases of atypical depression, some data indicate a reduction in activity of the HPA axis, and although patients with posttraumatic stress disorder (PTSD) show evidence of hyperactivity of the corticotrophin-releasing hormone receptor 1 (CRH$\mathrm{R} 1)$ pathways [10-12], this is accompanied by low plasma cortisol levels [13].

Recently, animal chronic stress models, based on the resident/intruder paradigm [14], have been developed to induce alterations in the HPA axis to study the relationship between the HPA axis and the development and treatment of psychopathologies, such as depression and PTSD [15-18]. Previous studies in our laboratory using the chronic social defeat stress model revealed that subjects who adopt a passive behavioral profile, which is characterized by a higher immobility and lower social and nonsocial exploration than the active subjects, have an exaggerated corticosterone response following repeated defeat and low resting levels of corticosterone several days after the end of the chronic defeat experience $[5,19]$. Human studies report similar patterns in cortisol levels following prolonged periods of stress [20, $21]$. These changes have been related to alterations in hypothalamic glucocorticoid receptors [5], corticotrophin-releasing hormone $(\mathrm{CRH})$ receptors in the pituitary gland [21], the response of the adrenal glands [22] and even changes in the amygdala and hippocampus [23]. However, the mechanisms responsible for this altered pattern of HPA axis activity as a result of stress are unclear. Studying the changes in $\mathrm{CRH}$ in relation to the coping strategies to stress and the role $\mathrm{CRH}$ plays in hormonal and autonomic coordination during the stress re- sponse may help improve our understanding of these mechanisms.

Studies analyzing the individual differences and activation of the SAM axis have found that subjects who adopt a more proactive coping strategy in response to a stressful stimulus have a greater sympathetic reactivity and lower plasma corticosterone response than the reactive subjects $[3,6,24]$. Nevertheless, it is unknown how chronic stress affects the activity of the SAM axis and its relationship with the development of psychopathologies that are associated with the type of coping strategy adopted. In humans, although some of the data are contradictory, a greater sympathetic reactivity has been found in patients with severe depression [25] and PTSD [26].

Despite evidence supporting the effectiveness of current antidepressants in the treatment of stress-related disorders, not all patients respond to treatment. CRH-R1 receptor antagonists are a new class of agents that have potential therapeutic use in the treatment of anxiety, depression and other stress-related disorders [11, 27]. Although some studies using animal models suggest that the acute blocking of CRH-R1 receptors has an anxiolytic and antidepressant effect, it is important to determine whether the chronic administration of these drugs constitutes a new treatment for these types of disorders [28].

The development of animal models to analyze the time course of physiological changes associated with different coping strategies may improve our understanding of the biological mechanisms involved in diverse pathologies and lead to more effective pharmacological treatments. In this study, we used a chronic defeat social stress model [18] to determine whether the corticosterone changes triggered by social stress as a function of the strategy adopted following social defeat are due to changes in $\mathrm{CRH}$ in the hypothalamus and amygdala. We assessed whether chronic stress results in different changes in the SAM system as a function of the strategy adopted by measuring plasma catecholamines and adrenal catecholamine synthesis enzymes at different times. We also investigated whether the physiological changes associated with passive coping strategies are related to the physiological changes observed in depressive-like disorders or PTSD. We hypothesized that these subjects would present a depressive-like phenotype in behavioral tests, such as the novel palatable test (NPT) and the forced swimming test (FST). Finally, we tested whether chronic treatment with antalarmin, a CRH-R1 antagonist, would reverse the effects of chronic stress on the HPA and SAM axes and behavior.
Pérez-Tejada/Arregi/Gómez-Lázaro/ Vegas/Azpiroz/Garmendia 


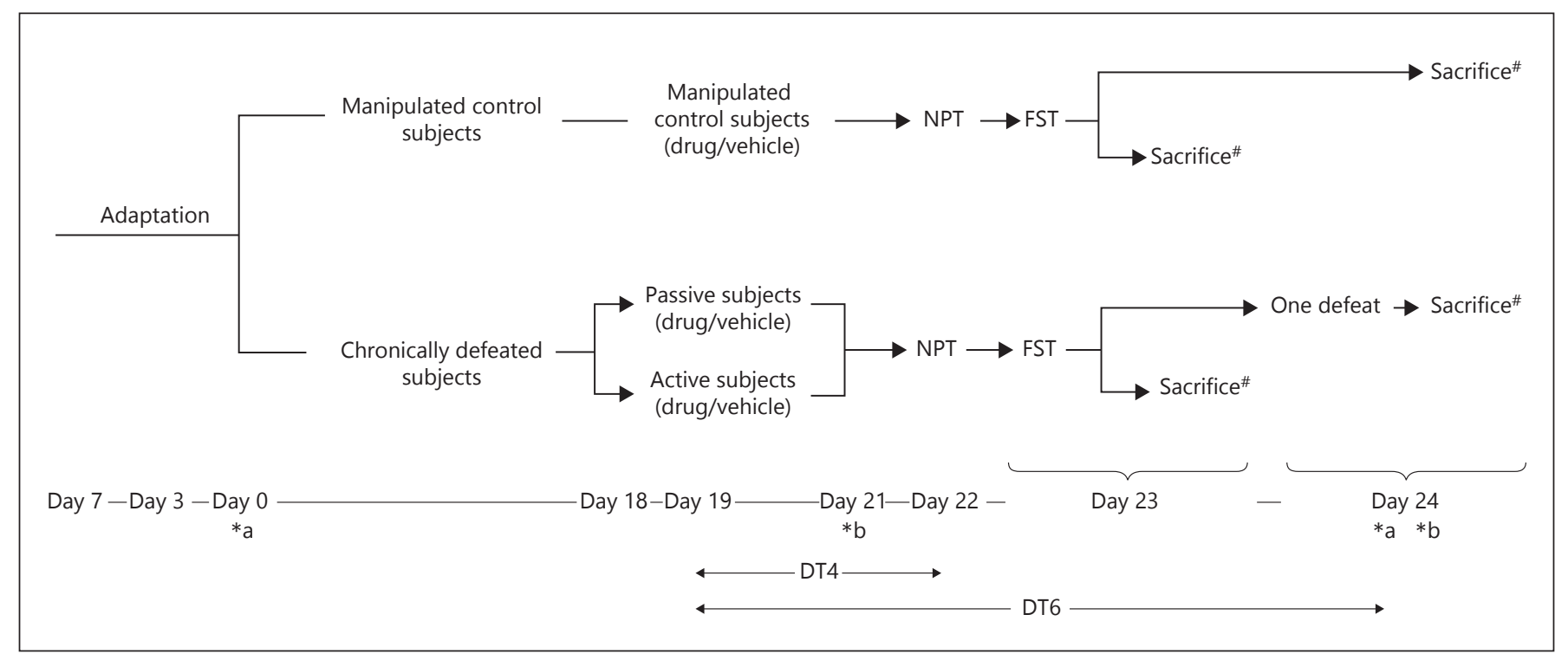

Fig. 1. Schematic representation of the experimental procedure. $* \mathrm{a}=$ Blood samples obtained by submandibular puncture at 8 a.m.; $* \mathrm{~b}=$ blood samples obtained by submandibular puncture after stress; DT4 = drug treatment for 4 days (starting on day 19 and

\section{Methods}

Animals and Husbandry

Six-week-old male OF1 mice (CRIFFA, Barcelona, Spain) were individually housed for 7 days in transparent plastic cages measuring $24.5 \times 24.5 \times 15 \mathrm{~cm}$ for adaptation to the laboratory conditions. Food and water were available ad libitum. The holding room was maintained at a constant temperature of $20^{\circ} \mathrm{C}$ with a 12 -hour light/ dark cycle (white lights on from 8:00 p.m. to 8:00 a.m.). The light cycle was reversed to facilitate behavior assessment during the animal's active phase (dark). All experimental procedures were conducted under dim red light conditions in a room adjacent to the holding facility. European regulations for the care and treatment of experimental animals were followed, and the procedures were controlled and approved by the Diputación Foral de Gipuzkoa, Spain, in compliance with the European Communities Council Directive (86/609/EEC) and the Ethics Committee of Basque Country University.

\section{Experimental Procedure}

The experiments were initiated after the adaptation period. A control group (manipulated control) and a group of socially stressed mice were established. Male adult mice were exposed to repeated defeat experiences for 21 days (at 11:00 a.m.). After a social stress period of 18 consecutive days, the behavior of the animals was recorded for subsequent assessment. The stressed mice were divided into two groups according to their behavioral profile during defeat: active and passive (see below). Treatment with antalarmin or vehicle was initiated at 10:00 a.m. for 4 days (for half of the stressed subjects, active and passive, which were sacrificed on day 23, prior to drug administration) or 6 days (for the remainder of the stressed subjects, active and passive, which were sacri- ending on day 22); DT6 = drug treatment for 6 days (starting on day 19 and ending on day 24). "The following samples were obtained: adrenal glands, hypothalamus and amygdala. ficed on day 24). The manipulated control group was also divided into drug and vehicle control groups, which were subjected to the same periods of treatment as the experimental groups. Therefore, a total of twelve groups were used. On day 21, the behavior in the confrontation was recorded again for subsequent assessment. On day 22 (at 8:30 a.m.), the animals were subjected to the NPT. On day 23 (at 9:00 a.m.), all of the subjects performed the FST, and $2 \mathrm{~h}$ later, when the acute stress response ended, half of the animals were sacrificed by cervical dislocation. On day 24 , the remaining animals were subjected to another social defeat. At 8:00 a.m. on days 0 and 24 (before the mice were subjected to defeat), and 40 min after defeat on days 21 and 24, blood samples (50-100 ml) were taken by submandibular puncture to measure the corticosterone and catecholamine levels. This new method [29] allowed us to obtain a sufficient volume of blood from the submandibular vein in a short time while holding the mouse without the use of anesthesia. On day 24, the animals were sacrificed by cervical dislocation $50 \mathrm{~min}$ after the last defeat. The brains from all of the animals were then quickly removed, and the whole hypothalamus and amygdala were dissected to measure CRH and CRH-R1 mRNA expression. All dissections were performed under stereomicroscopic observation with reference to the mouse brain atlas [30]. The adrenal glands were removed under sterile conditions and stored at $-70^{\circ} \mathrm{C}$ to measure dopamine $\beta$-hydroxylase (DBH) and tyrosine hydroxylase (TH) mRNA expression (fig. 1).

\section{Socially Stressed Mice}

The mice experienced repeated social defeat using the sensorial contact model [18]. Ninety-five pairs of mice matched by weight were allowed a 10-min confrontation, with half of the subjects being placed in their opponent's cage (i.e. in the cage of a resident mouse) for 3 successive days in order to select defeated 
subjects. After the third day, only those defeated subjects which had clearly shown submissive behavior during the agonistic confrontations, and their aggressive counterparts, continued with the experiment (85 pairs of mice). Between the fourth and last day of chronic stress, the defeated mice were exposed daily to $5 \mathrm{~min}$ of agonistic interactions with a different aggressive resident mouse. Daily transfer of males after the fighting precludes habituation of males to each other and consolidates the submissiveness of the defeated animal placed in an alien territory [31].

As a result, the mice were repeatedly defeated by a different aggressive resident mouse every day. After each daily confrontation, the mice were separated by transparent partitions with holes in the same cage in which the confrontation took place. These partitions permitted the mice to see, hear and smell each other, but prevented physical contact. Although the defeated mice received some bites during the direct interactions period, most of the mice did not have evident wounds. In the case of visible wounds, the mice were removed from the experimental procedure. The final number of defeated mice was 84 . The behaviors manifested by the defeated mice on days 18 and 21 during the 5 min of social interactions were recorded using video cameras (JVC, GZ-MG77E). The behavioral assessment was carried out using an ethogram for the mouse [32], in which 51 behaviors are described. These behaviors were divided into the following behavioral categories: avoidance/flee, defense/ submission, digging, self-grooming, exploration at a distance, immobility, nonsocial exploration and social exploration. The behavioral evaluation was carried out using The Observer 3.0 (Noldus ITC, Wageningen, the Netherlands). To classify the subjects according to behavior, two cluster analyses were performed on all of the defeated mice based on the behavioral characteristics they displayed in the social confrontation on days 18 and 21 using the mean percentage of time spent on each assessed behavioral element [19].

\section{Manipulated Controls}

The manipulated control group (31 subjects) was treated identically to the stressed group, but was not exposed to agonistic interactions or sensorial contact with other mice. These mice were housed individually in cages containing a transparent barrier to subject them to the same space restrictions as the experimental mice. The manipulated controls were moved daily to an experimentation room where the barrier was removed for the same period of time as that allotted to the confrontations in the defeated mice.

\section{Novel Palatable Test}

The mice were presented in the home cage with novel but highly palatable food, a peanut, on a petri dish once a day for 3 consecutive days (days 19-21). On day 4, when the latency to ingest the palatable food was expected to have decreased due to habituation to novelty and the hedonic response to the palatable food, the peanuts were presented in a normal housing cage where the bedding was changed $[33,34]$. The latency to eat the peanut was measured with a cutoff time of $600 \mathrm{~s}$.

\section{Forced Swimming Test}

Individual mice were placed in glass cylinders (height $18.5 \mathrm{~cm}$ and diameter $12.5 \mathrm{~cm}$ ) containing $13.5 \mathrm{~cm}$ of water at $25 \pm 1^{\circ} \mathrm{C}$. The test was performed over 1 day ( $48 \mathrm{~h}$ after the last defeat) for $5 \mathrm{~min}$, and was recorded for subsequent assessment [35]. The be- haviors assessed were immobility, swimming and climbing. Both the time spent engaged in each behavior and the swimming latency (defined as the immobility time until the mice started to swim) were measured. The mice were judged to be immobile when they ceased struggling and remained floating motionless in the water making only those movements necessary to keep their head above water.

\section{Drug}

The drug used was antalarmin, N-butyl-N-ethyl-2,5,6-trimethyl7-(2,4,6-trimethylphenyl)pyrrolo[3, 2-e]pyrimidin-4-amine, which was purchased from Sigma-Aldrich (Madrid, Spain) and dissolved in sterile saline containing 5\% dimethyl sulfoxide and 5\% Cremophor EL, which was also used for the vehicle injections. The drug was administered intraperitoneally according to bodyweight. Antalarmin was administered at $20 \mathrm{mg} / \mathrm{kg}$. These doses were chosen based on previous studies $[36,37]$. No evidence of toxic effects was observed after any of the drug treatments.

\section{Physiological Determinations}

Determination of Plasma Corticosterone and Catecholamine Concentrations

Blood was collected in vivo by submandibular vein puncture on days 0 and 24 before defeat (basal and resting), and on days 21 and 24 after stress in a heparinized container. The blood was then centrifuged at $1,800 \mathrm{~g}$ for $15 \mathrm{~min}$ at $4^{\circ} \mathrm{C}$. The resulting plasma was collected and stored at $-70^{\circ} \mathrm{C}$.

The plasma corticosterone concentration $(\mathrm{ng} / \mathrm{ml})$ was determined using a commercially available enzyme immunoassay kit (Assay Designs, Ann Arbor, Mich., USA) and an ELx 800 plate reader (BioTek Instruments Inc., Winooski, Vt., USA). The assay sensitivity was $5 \mathrm{pg} / \mathrm{ml}$, and the intra- and interassay variation coefficients were 7 and $8 \%$, respectively.

The plasma noradrenaline and adrenaline concentrations (ng/ $\mathrm{ml}$ ) were determined using ELISA kits. Serum A and NA content kits were obtained from Labor Diagnostica Nord GmbH \& Co. KG (Laboratorios Leti, Spain). The plates were read at $450 \mathrm{~nm}$ using an ELx 800 plate reader (BioTek Instruments Inc.). The detection limits were $0.3 \mathrm{ng} / \mathrm{ml}$ (with intra and interassay variation coefficients of $11.2-16.3 \%$ and $8.7-12.6 \%$, respectively).

\section{Real-Time RT-PCR Measurements of mRNA Expression}

Tissue from the adrenal gland, hypothalamus and amygdala were homogenized using the TRIzol reagent (Invitrogen, Madrid, Spain), and total RNA was isolated using the standard phenol: chloroform extraction method [38]. A UV spectrophotometric analysis of nucleic acids was performed at $260 \mathrm{~nm}$ to determine the RNA concentrations, and the 260:280 absorbance ratio was used to assess the nucleic acid purity. The samples were DNase treated (DNase I; Invitrogen) to remove contaminating DNA prior to cDNA synthesis, and the total RNA was reverse transcribed using PrimeScript reverse transcriptase (Conda, Madrid, Spain). The resulting cDNA underwent SYBR Green-based (QuantiTect SYBR Green PCR; Conda) real-time PCR, and the amplification was monitored using the Applied Biosystems 7500 Real-Time PCR System. The cDNA sequences were obtained from GenBank at the National Center for Biotechnology Information (www.ncbi.nlm. nih.gov), and glyceraldehyde-6-phosphate dehydrogenase was used as a housekeeping gene. The primer sequences were designed using Primer Express Software v3.0 (Applied Biosystems, Madrid, 
Table 1. PCR primer specifications

\begin{tabular}{|c|c|c|}
\hline Gene & Primer sequence $\left(5^{\prime}-3^{\prime}\right)$ & GenBank accession No. \\
\hline $\mathrm{CRH}$ & $\begin{array}{ll}\text { F: } & \text { TCTGCGGGAAGTCTTGGAAA } \\
\text { R: } & \text { TCCTGTTGCTGTGAGCTTGCT }\end{array}$ & NM_205769.2 \\
\hline CRH-R1 & $\begin{array}{ll}\text { F: } & \text { TGTTCGGTGAGGGCTGCTA } \\
\text { R: } & \text { CGGTCGGTGGAGTACGTGAGT }\end{array}$ & NM_007762.4 \\
\hline $\mathrm{TH}$ & $\begin{array}{ll}\text { F: } & \text { CTTCTCTGACCAGGCGTATCG } \\
\text { R: } & \text { ATTGGCTCACCCTGCTTGTATT }\end{array}$ & NM_009377.1 \\
\hline $\mathrm{DBH}$ & $\begin{array}{ll}\text { F: } & \text { TTACCACAACCCACGGAAGATAC } \\
\text { R: } & \text { CATCATAGCGTCGGAGAGTAGCT }\end{array}$ & NM_138942.3 \\
\hline GAPDH & $\begin{array}{ll}\text { F: } & \text { CGGCCGCATCTTCTTGTG } \\
\text { R: } & \text { GTGACCAGGCGCCCAATAC }\end{array}$ & NM_008084.2 \\
\hline
\end{tabular}

GAPDH = Glyceraldehyde-6-phosphate dehydrogenase.

Spain; table 1). The primers were obtained from Applied Biosystems, and the specificity of the primers was verified by a melting curve analysis. The relative gene expression was determined using the $2-\Delta \Delta \mathrm{t}$ method [39].

\section{Statistical Analysis}

All statistical analyses were carried out using SPSS 15.0 for Windows (SPSS Inc., Chicago, Ill., USA) with the level of significance set at $\mathrm{p} \leq 0.05$. The social behavioral variables were analyzed using hierarchical cluster and multivariate discriminant analyses (see socially stressed mice). The behavioral and physiological variables were analyzed using one-way or two-way ANOVAs. Threeway ANOVAs for repeated measures were used to analyze social behavior and the catecholamine and corticosterone levels. When appropriate, specific comparisons were made using post hoc Tukey's tests.

\section{Results}

Analysis of the Behavioral Profile during Chronic

Defeat and the Effect of Antalarmin Administration

A cluster analysis using the mean percentage of time spent on each assessed behavioral element was carried out on all defeated mice on day 18 to separate the mice into groups based on the behavioral characteristics they demonstrated during the social confrontation. This analysis resulted in two final clusters. The multivariate discriminant analysis confirmed the statistical validity of the established groups and accounted for $95.6 \%$ of the cases obtained by the cluster solution, thus confirming the behavioral descriptions. The variables that best discriminated between the two clusters were immobility and nonsocial and social exploration. Cluster $1(n=45)$, designated the 'active group', was characterized by a high level of exploratory behaviors, especially nonsocial exploration. Cluster $2(\mathrm{n}=39)$ was characterized by mice that spent most of their time immobile. The group of mice that belonged to this second cluster was termed the 'passive group'. The passive subjects had higher levels of immobility $(\mathrm{F}[1,82]=77.061, \mathrm{p} \leq 0.001)$ and lower levels of nonsocial exploration $(\mathrm{F}[1,82]=101.524, \mathrm{p} \leq$ $0.001)$, social exploration $(\mathrm{F}[1,82]=54.377, \mathrm{p} \leq 0.001)$, digging $(\mathrm{F}[1,82]=7.750, \mathrm{p}<0.01)$ and self-grooming $(\mathrm{F}[1,82]=8,388, \mathrm{p}<0.01)$ than their more active counterparts (table 2).

When a three-way ANOVA (i.e. time, group and treatment) using repeated measures from days 18 and 21 was performed, significant differences were observed for the group factor $(\mathrm{F}[1,72]=15.170, \mathrm{p} \leq 0.0001)$ and time $\times$ group interaction $(F[1,72]=3.699, \mathrm{p}<0.001)$. However, no significant differences from the drug treatment were observed $(\mathrm{F}[1,72]=0.699)$. According to the group factor, the ANOVA revealed that the passive subjects had higher levels of immobility $(\mathrm{F}[1,79]=77.061, \mathrm{p} \leq 0.001)$ and lower levels of nonsocial exploration $(\mathrm{F}[1,79]=$ $101.524, \mathrm{p} \leq 0.001)$, exploration at a distance $(\mathrm{F}[1,79]=$ $54.377, \mathrm{p} \leq 0.001)$, self-grooming $(\mathrm{F}[1,79]=8,388, \mathrm{p}<$ $0.005)$ and digging $(\mathrm{F}[1,79]=7.750, \mathrm{p}<0.01)$ behaviors than their active counterparts. The analysis of the time $x$ group interaction revealed that the behaviors found to be significant were nonsocial exploration $(\mathrm{F}[1,79]=15.724$, $\mathrm{p}<0.01)$, exploration at a distance $(\mathrm{F}[1,79]=12.699, \mathrm{p}<$ $0.001)$, immobility $(\mathrm{F}[1,79]=17.301, \mathrm{p} \leq 0.001)$ and digging $(F[1,79]=5.381, p<0.05)$. Specifically, in the passive subjects, a reduction was observed in nonsocial explora- 
Table 2. Means of the percentage of time ( \pm SEM) dedicated to each of the behaviors analyzed in terms of group membership, active $(\mathrm{n}=44)$ and passive $(\mathrm{n}=40)$, on days 18 and 21 of chronic social stress

\begin{tabular}{|c|c|c|c|c|c|c|c|c|}
\hline Social behavior & \multicolumn{3}{|l|}{ Day 18} & \multicolumn{3}{|l|}{ Day 21} & \multicolumn{2}{|c|}{ Day 18 vs. day 21} \\
\hline Social exploration & $2.56 \pm 0.82$ & $>* * *$ & $1.02 \pm 0.64$ & $2.58 \pm 1.4$ & $>^{*}$ & $0.15 \pm 0.8$ & $=$ & $=$ \\
\hline Nonsocial exploration & $25.09 \pm 0.32$ & $>* * *$ & $18.64 \pm 1.41$ & $26.09 \pm 1.39$ & $>^{* * *}$ & $12.25 \pm 1.12$ & $=$ & $\downarrow * * *$ \\
\hline Exploration at a distance & $2.35 \pm 0.90$ & $=$ & $2.08 \pm 0.07$ & $2.06 \pm 1.02$ & $>^{* * *}$ & $0.65 \pm 0.11$ & $=$ & $\downarrow * * *$ \\
\hline Defense/submission & $12.34 \pm 0.98$ & $=$ & $13.39 \pm 1.49$ & $11.52 \pm 1.80$ & $<* * *$ & $14.71 \pm 0.80$ & $=$ & $=$ \\
\hline Digging & $0.25 \pm 0.1$ & $>^{* *}$ & $0.10 \pm 0.01$ & $0.06 \pm 0.01$ & $=$ & $0.22 \pm 0.02$ & $=$ & $\uparrow *$ \\
\hline Self-grooming & $3.61 \pm 0.93$ & $>^{* *}$ & $1.59 \pm 0.77$ & $3.18 \pm 1.04$ & $>^{* * *}$ & $1.47 \pm 0.04$ & $=$ & $=$ \\
\hline
\end{tabular}

$\uparrow$ Increase; $\downarrow$ decrease; $=$ no change. ${ }^{*} \mathrm{p}<0.05 ;{ }^{* *} \mathrm{p}<0.01 ;{ }^{* * *} \mathrm{p}<0.001$.

tion and exploration at a distance and there was an increase in immobility and digging. The active subjects, however, had increased immobility from day 18 to day 21 of social stress (table 2).

Because the drug did not affect the behavior of the mice, a second and definitive cluster analysis was carried out on all of the defeated mice on day 21 . This cluster analysis resulted in two final clusters. The multivariate discriminant analysis confirmed the statistical validity of the established groups and accounted for $97.4 \%$ of the cases obtained by the cluster solution. The variables that best discriminated between the two clusters were nonsocial and social exploration. Cluster $1(n=44)$, which was designated the 'active group', was characterized by high exploratory behaviors. Cluster $2(\mathrm{n}=40)$, which was defined as the 'passive group', was characterized by lower levels of social and nonsocial exploration. Additionally, on day 21 of social stress, the passive subjects had increased immobility $(\mathrm{F}[1,82]=13.224, \mathrm{p} \leq 0.001)$, defense/submission $(\mathrm{F}[1,82]=24.168, \mathrm{p} \leq 0.001)$ and avoidance/flee $(\mathrm{F}[1,82]=15.864, \mathrm{p} \leq 0.001)$ behaviors, and decreased nonsocial exploration $(\mathrm{F}[1,82]=107.175$, $\mathrm{p} \leq$ $0.001)$, social exploration $(\mathrm{F}[1,82]=4.777, \mathrm{p}<0.05)$, exploration at a distance $(\mathrm{F}[1,82]=13.286, \mathrm{p} \leq 0.001)$ and self-grooming $(\mathrm{F}[1,82]=14.205, \mathrm{p} \leq 0.001)$ behaviors compared to their more active counterparts (table 2 ).

\section{Novel Palatable Test}

The analysis of the latency to ingest the palatable food on day 22 showed a significant effect for the group factor $(\mathrm{F}[2,110]=5.053, \mathrm{p}<0.01)$. A post hoc analysis revealed that both the passive $(\mathrm{p}<0.05)$ and active $(\mathrm{p}=0.05)$ sub-

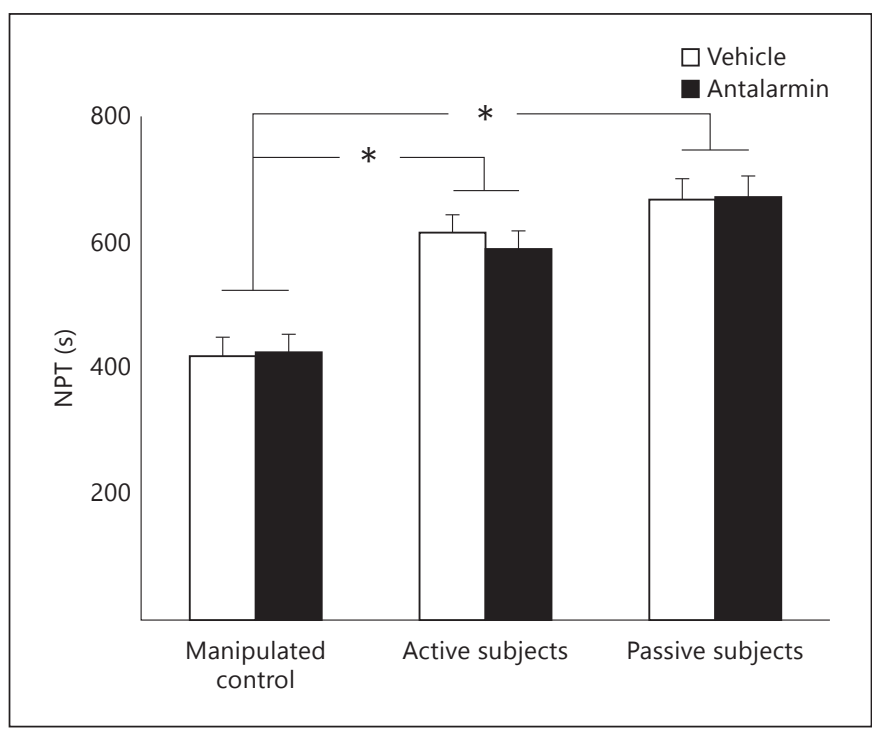

Fig. 2. The graph shows the means $( \pm$ SEM) of latency to ingest the novel palatable food (s) on day 22. Six groups are represented: manipulated control-vehicle $(\mathrm{n}=15)$, manipulated control-antalarmin $(\mathrm{n}=$ $16)$, active-vehicle $(n=22)$, active-antalarmin $(n=22)$, passive-vehicle $(n=20)$ and passive-antalarmin $(n=20) .{ }^{*} p<0.05$ (Tukey's tests).

jects had a higher latency than the manipulated control group. No significant effect from the drug treatment was observed $(F[1,110]=0.012$; fig. 2$)$.

\section{Forced Swimming Test}

ANOVA of the data obtained during the FST on day 23 showed a significant effect for immobility $(\mathrm{F}[2,98]=$ $3.336, \mathrm{p}<0.05)$ and swimming latency $(\mathrm{F}[2,98]=3.811$, 


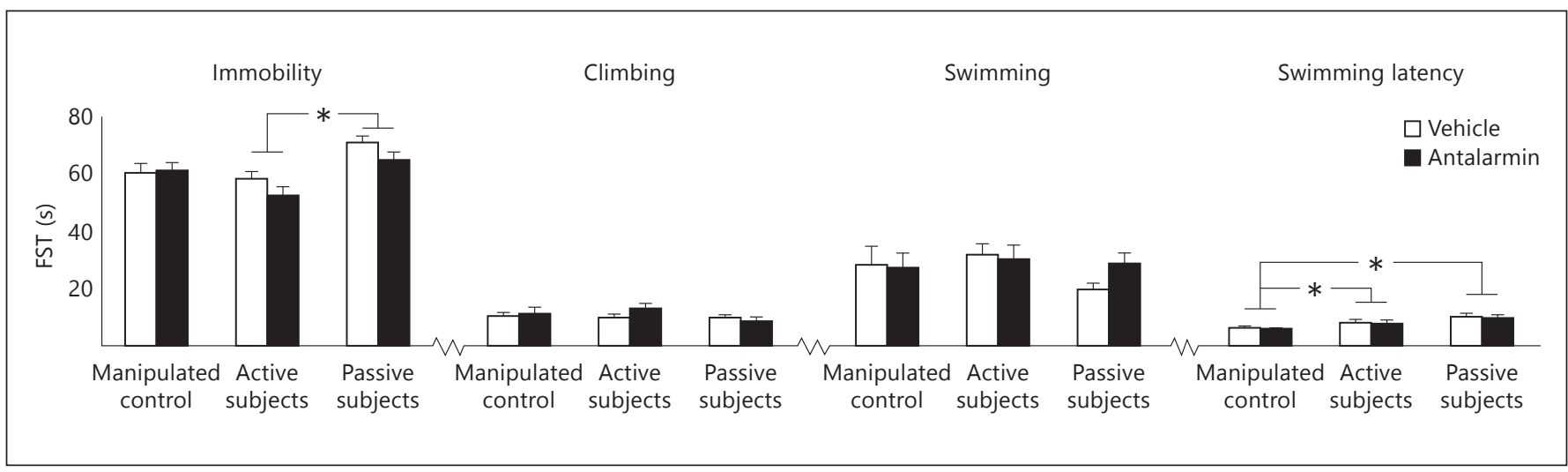

Fig. 3. The graph shows the means ( \pm SEM) of immobility, swimming, climbing and swimming latency (s) in the FST on day 23. Six groups are represented: manipulated control-vehicle $(n=15)$, ma- nipulated control-antalarmin $(\mathrm{n}=16)$, active-vehicle $(\mathrm{n}=22)$, active antalarmin $(n=22)$, passive-vehicle $(n=20)$ and passive-antalarmin $(\mathrm{n}=20){ }^{*} \mathrm{p}<0.05$ (Tukey's tests). $\mathrm{p}<0.05)$. A post hoc analysis revealed that the passive group had increased immobility $(\mathrm{p}<0.05)$ compared to the active group, and both groups of stressed subjects had a higher swimming latency than the manipulated control group ( $\mathrm{p}<0.05$; fig. 3 ). No significant differences between the groups were observed for the remainder of the measured variables [time spent swimming $(\mathrm{F}[2,98]=2.192)$ and climbing $(F[2,98]=1.269)]$. No significant effect from the drug treatment was observed for immobility $(\mathrm{F}[1,98]=2.450)$, swimming $(\mathrm{F}[1,98]=1.138)$, climbing $(\mathrm{F}[1,98]=0.934)$ and swimming latency $(\mathrm{F}[1,98]=$ 2.673).

\section{Analysis of Physiological Parameters}

Plasma Corticosterone Concentration

The three-way ANOVA (i.e. time, group and treatment) using repeated measures from days 21 and 24 (following defeat) revealed significant differences for the group factor $(\mathrm{F}[2,47]=29.541, \mathrm{p}=0.001)$ and time $\times$ group interaction $(\mathrm{F}[2,47]=10.080, \mathrm{p}<0.01)$. Specifically, the post hoc analysis revealed that the passive subjects had higher levels of corticosterone in their plasma than the active subjects $(\mathrm{p}<0.05)$ and manipulated controls $(\mathrm{p}<0.01)$, and the active subjects had higher levels than the manipulated controls $(\mathrm{p}<0.01)$. A reduction in corticosterone levels was observed in the passive subjects $(\mathrm{F}[1,20]=10.738, \mathrm{p}<0.01)$ and manipulated controls $(\mathrm{F}[1,14]=6.142, \mathrm{p}<0.05)$ between days 21 and 24 . However, no significant effect from the drug treatment was observed $(F[1,46]=0.031)$. When corticosterone levels on day 21 were analyzed, a significant effect of the group factor was found $(\mathrm{F}[2,106]=24.661, \mathrm{p} \leq 0.0001)$. Post hoc analysis revealed that the passive subjects had higher corticosterone levels than both the active subjects $(\mathrm{p}<0.01)$ and manipulated controls ( $\mathrm{p}<0.01$; fig. 4 ). No significant effect from the drug treatment was observed $(F[1,106]=$ 2.392). On day 24 following the defeat, significant differences were observed between the groups $(\mathrm{F}[2,49]=$ $22.458, \mathrm{p} \leq 0.0001)$. Specifically, the stressed mice had higher concentrations of corticosterone than the manipulated controls ( $\mathrm{p} \leq 0.0001$; fig. 4 ), but no differences were observed between the active and passive subjects. No significant effect from the drug treatment was observed ( $F[1$, $49]=0.072$ ).

A three-way ANOVA (i.e. time, group and treatment) with repeated measures using the basal corticosterone levels from day 0 , before the social stress began, and the resting corticosterone levels from day 24 (before defeat) indicated that there was a significant effect for the time $x$ group interaction $(\mathrm{F}[2,46]=3.275, \mathrm{p}<0.05)$. A reduction in corticosterone levels was observed between days 0 and 24 in the passive subjects $(F[1,20]=12.110, p<0.01)$. No significant effect from the drug treatment was observed $(\mathrm{F}[2,46]=0.957)$. The analysis of the corticosterone basal levels on day 0 revealed no differences between the groups $(F[1,109]=0.034)$. When we analyzed the corticosterone resting levels obtained on day 24 , there were significant differences between the groups $(\mathrm{F}[2,48]=$ $3.385, \mathrm{p}<0.05)$. Post hoc analyses revealed that the passive mice had lower concentrations of corticosterone than the manipulated controls $(\mathrm{p}=0.05$; fig. 4$)$. No differences were observed between the active mice and passive and manipulated control mice. No significant effect from the drug treatment was observed $(\mathrm{F}[1,48]=0.611)$. 


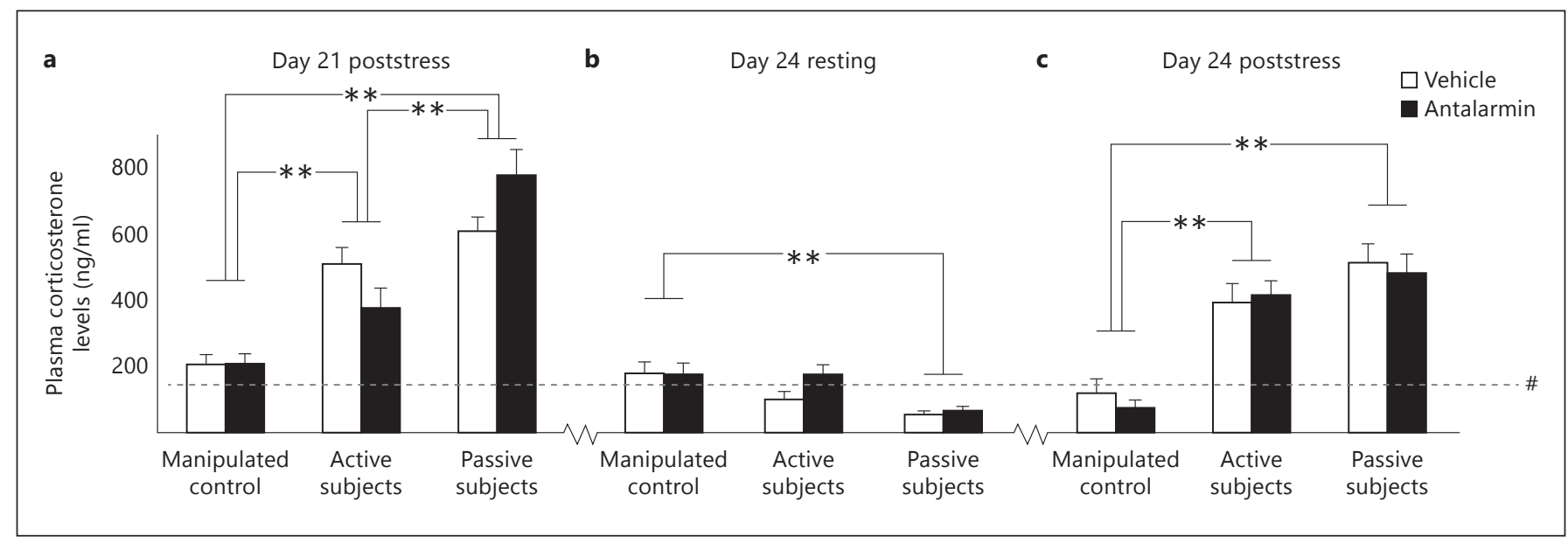

Fig. 4. a Plasma corticosterone concentrations ( $\mathrm{ng} / \mathrm{ml}$ ) obtained by submandibular puncture on day 21 following defeat. Six groups are represented: manipulated control-vehicle $(n=15)$, manipulated control-antalarmin $(n=16)$, active-vehicle $(n=22)$, activeantalarmin $(n=22)$, passive-vehicle $(n=20)$ and passive-antalar$\min (\mathrm{n}=20)$. $\mathbf{b}$ Corticosterone resting levels measured on day 24 , 3 days following the defeat on day 21 . c Corticosterone levels fol-

Plasma Noradrenaline and Adrenaline

Concentration

When a three-way ANOVA (i.e. time, group and treatment) using repeated measures from days 21 and 24 (following defeat) was performed, no significant differences were observed for either the group factor (noradrenaline: $\mathrm{F}[2,43]=1.956$; adrenaline: $\mathrm{F}[2,43]=0.236$ ) or the drug treatment factor (noradrenaline: $\mathrm{F}[1,43]=$ 1.328; adrenaline: $F[1,43]=0.048$ ). A separate analysis of the catecholamine data obtained after 21 days of defeat also showed no significant effect for either the group factor (noradrenaline: $\mathrm{F}[1,43]=0.160$; adrenaline: $\mathrm{F}[1$, $43]=1.545$ ) or the drug treatment factor (noradrenaline: $\mathrm{F}[1,43]=0.423$; adrenaline: $\mathrm{F}[1,43]=1.147)$. However, on day 24 after the defeat, a significant effect of the group factor was observed for the noradrenaline and adrenaline levels (noradrenaline: $\mathrm{F}[2,43]=3.584, \mathrm{p}<0.05$; adrenaline: $\mathrm{F}[1,43]=3.945, \mathrm{p}<0.05)$. Specifically, the passive subjects had lower noradrenaline levels than the manipulated controls $(\mathrm{p}=0.05)$ and lower adrenaline levels than their active counterparts ( $\mathrm{p}<0.05$; fig. 5 ). No significant effect from the drug treatment was observed (noradrenaline: $\mathrm{F}[2,43]=0.587$; adrenaline: $\mathrm{F}[1,43]=$ $0.949)$.

A three-way ANOVA (i.e. time, group and treatment) with repeated measures on the basal catecholamine levels from day 0 and the resting catecholamine levels from day lowing the defeat on day 24. In graphs $\mathbf{b}$ and $\mathbf{c}$, the following groups are represented: manipulated control-vehicle $(\mathrm{n}=8)$, manipulated control-antalarmin $(n=8)$, active-vehicle $(n=11)$, active-antalar$\min (\mathrm{n}=11)$, passive-vehicle $(\mathrm{n}=10)$ and passive-antalarmin $(\mathrm{n}=$ 10). The data are expressed as means \pm SEM. ${ }^{\#}=$ Mean of plasma corticosterone levels of all groups, obtained on day 0 before defeat $(\overline{\mathrm{x}}=165.86) .^{*} \mathrm{p}<0.05 ;{ }^{* *} \mathrm{p}<0.01$ (Tukey's tests).

24 (before defeat) showed no significant effect for either the group factor (noradrenaline: $\mathrm{F}[2,43]=0.198$; adrenaline: $\mathrm{F}[1,43]=0.508$ ) or the drug treatment factor (noradrenaline: $\mathrm{F}[2,43]=1.977$; adrenaline: $\mathrm{F}[1,43]=0.664$ ). A separate analysis of the catecholamine basal levels on day 0 also revealed no significant differences between the groups (noradrenaline: $\mathrm{F}[1,43]=1.117$; adrenaline: $\mathrm{F}[1$, $43]=0.823$ ) or for drug treatment (noradrenaline: $\mathrm{F}[1$, $43]=1.955$; adrenaline: $\mathrm{F}[1,43]=1.420)$. The noradrenaline and adrenaline resting levels obtained on day 24 showed a significant effect from the drug treatment (noradrenaline: $F[1,43]=10.599, \mathrm{p}<0.005$; adrenaline: $\mathrm{F}[1$, $43]=3.972, \mathrm{p}=0.05)$, with animals treated with antalarmin having lower noradrenaline and adrenaline levels (fig. 5). No significant effects were observed for the group factor (noradrenaline: $F[1,43]=1.328$; adrenaline: $F[1$, $43]=0.286)$.

mRNA Expression of TH and DBH in the Adrenal Glands

When analyzing the levels of mRNA for the catecholamine synthesis enzymes on day 23, which was 2 days after the defeat on day 21 (resting levels), the two-way ANOVA (group and treatment) revealed a significant effect on the group factor (TH: $F[2,40]=3,665, \mathrm{p}<0.05$; $\mathrm{DBH}: \mathrm{F}[2,40]=4,464, \mathrm{p}<0.05)$. Post hoc analyses revealed that the active subjects had higher $\mathrm{TH}$ and $\mathrm{DBH}$ 


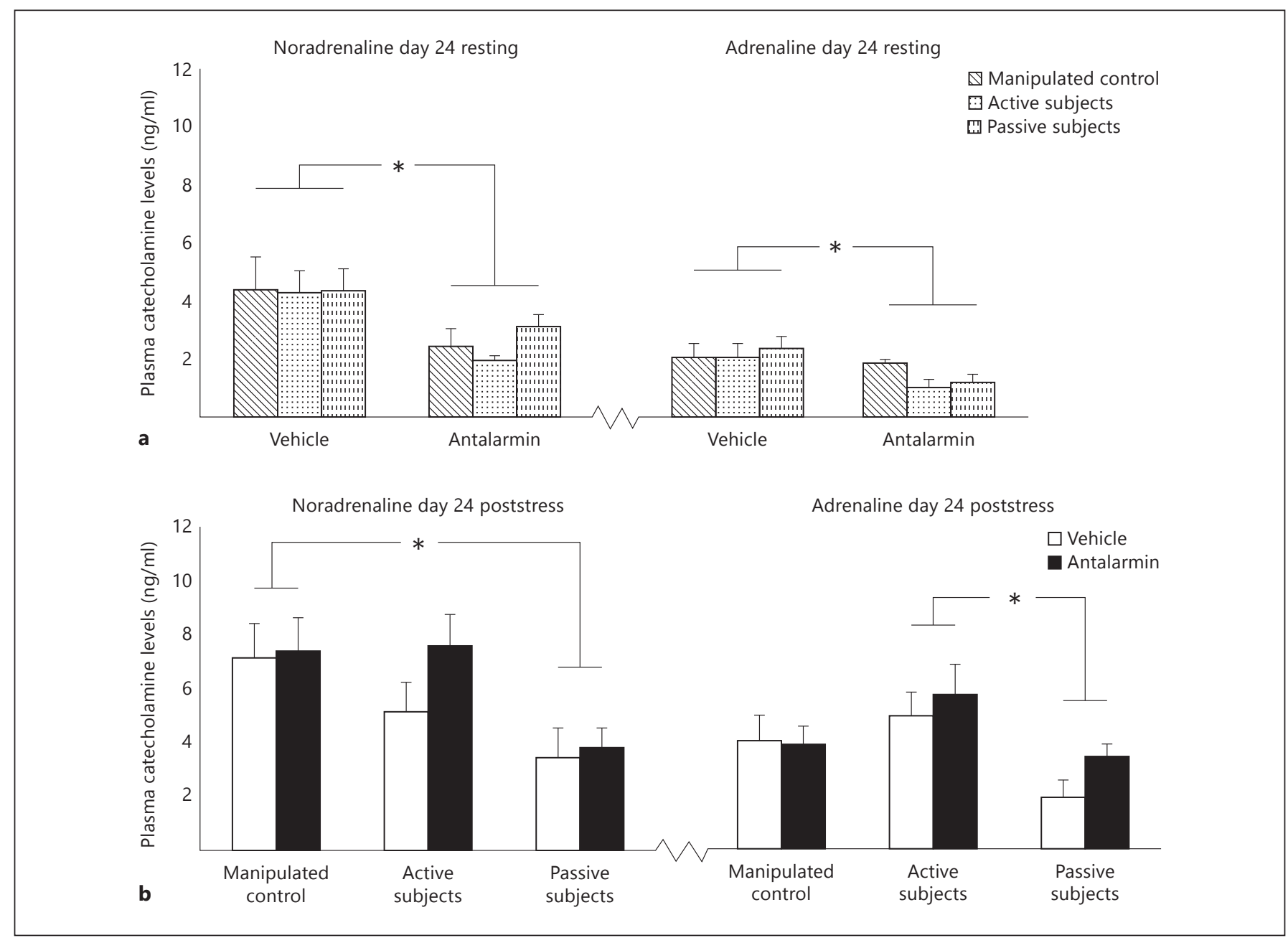

Fig. 5. a Catecholamine resting levels measured on day 24 before defeat. The following six groups are represented: manipulated control-vehicle $(n=7)$, manipulated control-antalarmin $(n=7)$, active-vehicle $(\mathrm{n}=7)$, active-antalarmin $(\mathrm{n}=8)$, passive-vehicle $(\mathrm{n}=$ 8 ) and passive-antalarmin $(n=8)$. b Catecholamine levels on day

mRNA expression than the manipulated controls $(\mathrm{p}<$ 0.05 for both enzymes; fig. 6). No significant effect from the drug treatment was observed $(\mathrm{TH}: \mathrm{F}[2,40]=0.333$; DBH: $\mathrm{F}[2,40]=0.152$ ).

The analysis of the TH and DBH mRNA expression levels following the defeat on day 24 revealed an effect on the group factor (TH: $\mathrm{F}[2,43]=3,691, \mathrm{p}<0.05 ; \mathrm{DBH}: \mathrm{F}[2$, $43]=5,077, \mathrm{p}<0.05)$. Specifically, the analysis revealed that the active subjects had higher TH and DBH mRNA expression levels than the passive subjects (TH: $\mathrm{p}<0.05$; DBH: $\mathrm{p}<0.01$; fig. 6). No significant effect from the drug treatment was observed (TH: F[2, 43] $=1.568 ; \mathrm{DBH}: \mathrm{F}[2$, $43]=0.252)$.

Coping with Chronic Social Stress
24 following defeat. The following groups are represented: manipulated control-vehicle $(\mathrm{n}=7)$, manipulated control- antalarmin $(n=8)$, active-vehicle $(n=7)$, active-antalarmin $(n=8)$, passive-vehicle $(\mathrm{n}=7)$ and passive-antalarmin $(\mathrm{n}=8)$. Data are expressed as means \pm SEM. ${ }^{*} \mathrm{p}<0.05$ (Tukey's tests).

mRNA Expression of CRH and CRH-R1 in the Hypothalamus and Amygdala

Upon analyzing levels of CRH mRNA in the hypothalamus on day 23, which was 2 days after the defeat on day 21 (resting levels), the two囚way ANOVA (group and treatment) revealed a significant effect of the group factor $(\mathrm{F}[2,45]=3,869, \mathrm{p}<0.05)$, with the passive subjects having higher $\mathrm{CRH}$ levels than their active counterparts (fig. 7). No significant effect from the drug treatment was observed $(F[2,45]=2.289)$. No significant effect was observed on the resting levels of CRH mRNA in the amygdala (group factor: $\mathrm{F}[2,45]=0.142$; drug treatment factor: $\mathrm{F}[2,45]=3.214)$. The analysis of CRH-R1 mRNA 


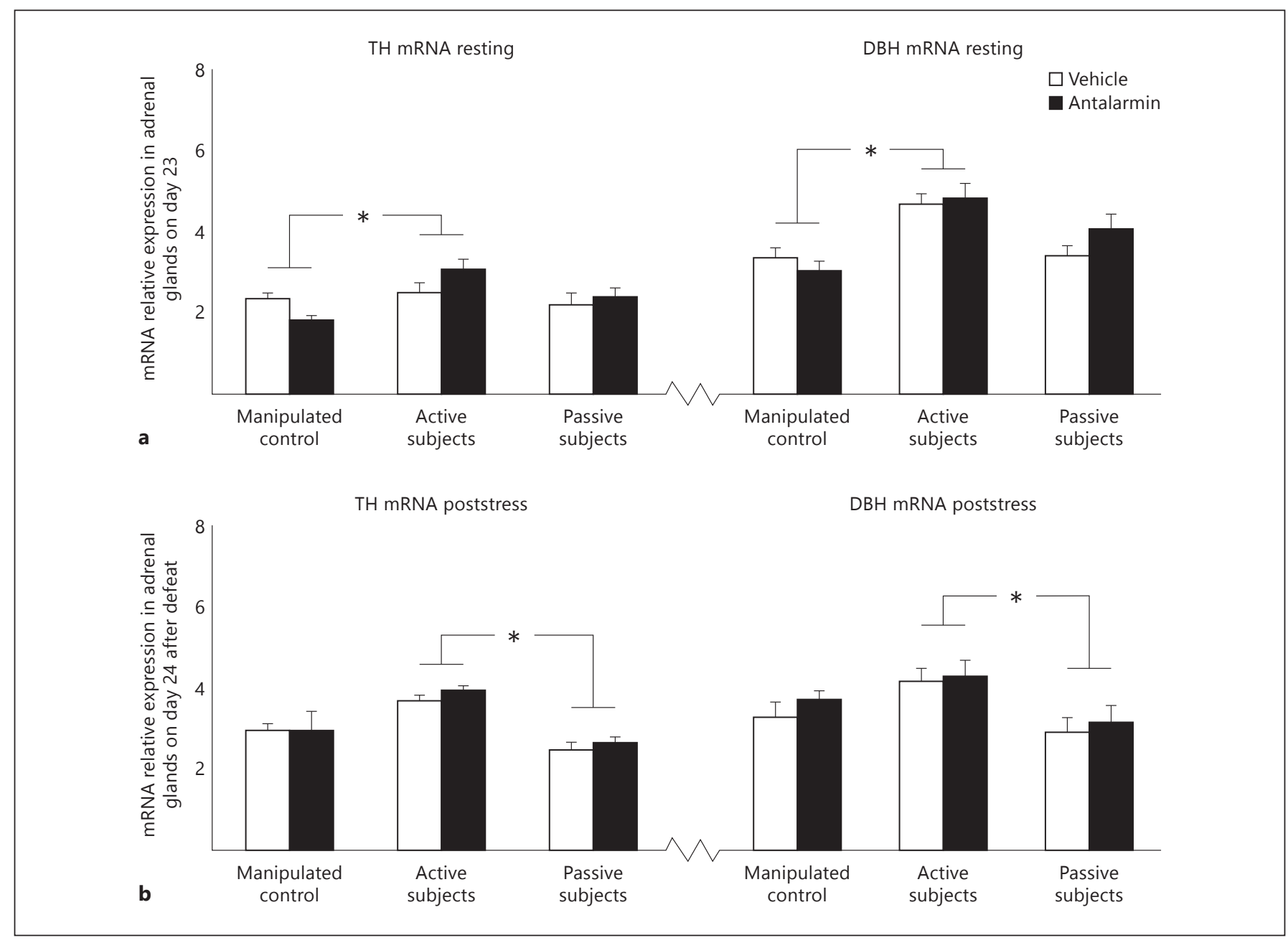

Fig. 6. a Resting mRNA expression of TH and DBH in the adrenal glands of the different groups analyzed on day 23, 2 days after the defeat on day 21: manipulated control-vehicle $(n=7)$, manipulated control-antalarmin $(\mathrm{n}=8)$, active-vehicle $(\mathrm{n}=11)$, active-antalarmin $(\mathrm{n}=11)$, passive-vehicle $(\mathrm{n}=10)$ and passiveantalarmin $(\mathrm{n}=10)$. $\mathbf{b}$ mRNA expression of TH and $\mathrm{DBH}$ in the adrenal glands of the different groups analyzed on day 24 following defeat: manipulated control-vehicle $(\mathrm{n}=8)$, manipulated control-antalarmin $(n=8)$, active-vehicle $(n=11)$, active-antalarmin $(\mathrm{n}=11)$, passive-vehicle $(\mathrm{n}=10)$ and passive-antalarmin $(\mathrm{n}=10)$. Data are expressed means \pm SEM. ${ }^{*} \mathrm{p}<0.05$ (Tukey's tests). expression on day 23 revealed no differences in the hypothalamus (group factor: $\mathrm{F}[2,45]=0.620$; drug treatment factor: $F[2,45]=0.180$ ) or the amygdala (group factor: $F[2,45]=0.171$; drug treatment factor: $F[2,45]=$ $0.023)$.

The data obtained on day 24 after the social defeat revealed that all of the stressed subjects had higher levels of CRH mRNA expression $(\mathrm{F}[1,45]=4.392, \mathrm{p}<0.05)$ and lower levels of CRH-R1 mRNA expression in the hypothalamus $(\mathrm{F}[1,45]=4.135, \mathrm{p}<0.05)$ than the manipulated controls (fig. 7). No significant effect was observed for the group factor (CRH: F[2, 45] = 2.522; CRH-R1: F[2,
$45]=1.816)$ or drug treatment $(\mathrm{CRH}: \mathrm{F}[2,45]=0.076$; CRH-R1: F $[2,45]=3.082$ ). In the amygdala, the two-way ANOVA (group and treatment) revealed a significant effect of the group factor $(\mathrm{F}[2,45]=3.467, \mathrm{p}<0.05)$ on $\mathrm{CRH}$ mRNA expression. Post hoc analyses revealed that the passive subjects had higher CRH mRNA expression levels than the manipulated controls ( $\mathrm{p}<0.05$; fig. 7$)$. No significant effect from the drug treatment was observed $(\mathrm{F}[2,45]=0.161)$. The analysis of CRH-R1 receptor expression levels in the amygdala revealed no significant differences (group factor: $\mathrm{F}[2,45]=1.919$; drug treatment: $\mathrm{F}[2,45]=1.242)$. 

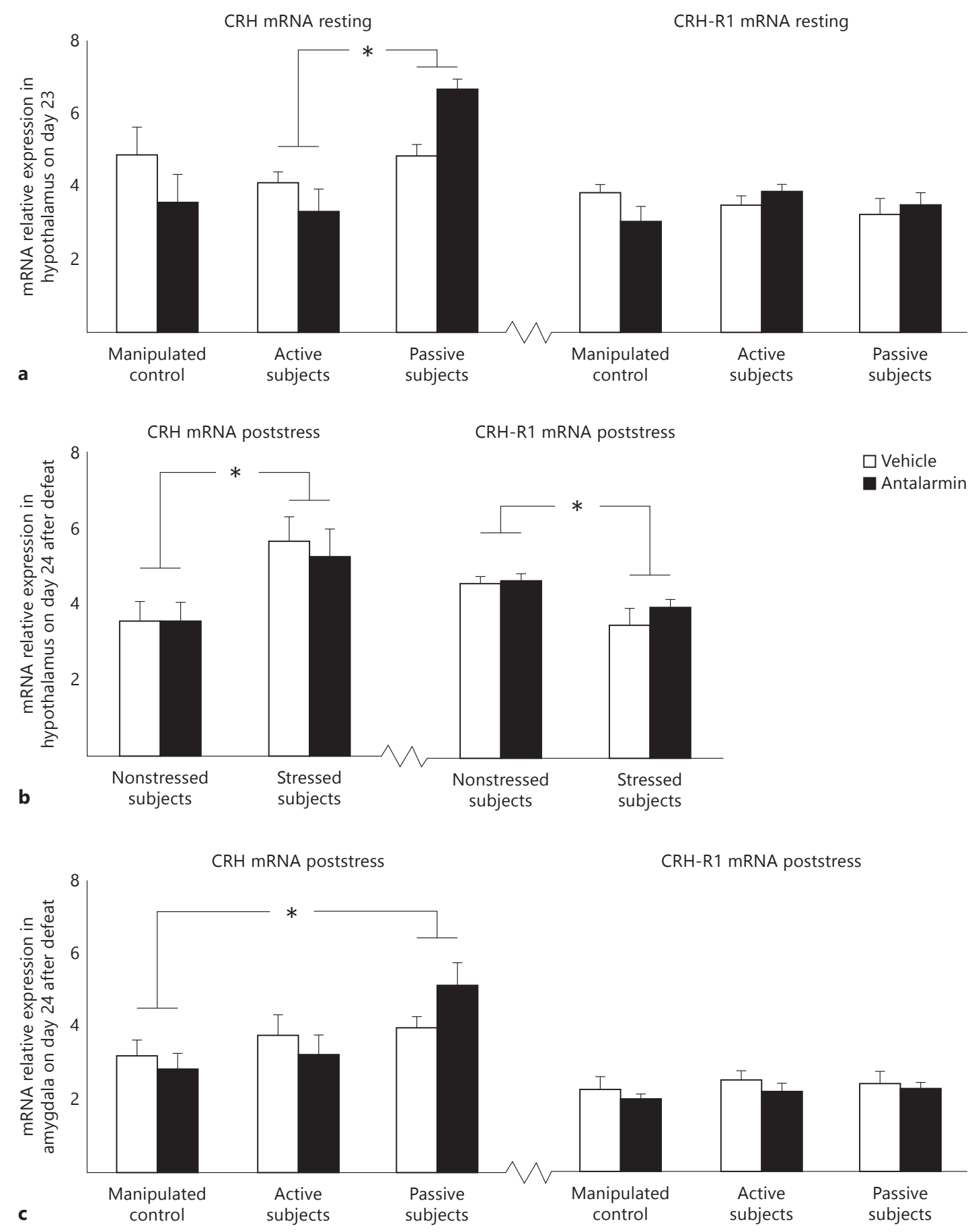

Fig. 7. a Resting mRNA expression of $\mathrm{CRH}$ in the hypothalamus of the different groups analyzed on day 23, 2 days after the defeat on day 21: manipulated control-vehicle $(n=7)$, manipulated control-antalarmin $(\mathrm{n}=8)$, active-vehicle $(\mathrm{n}=11)$, active-antalarmin $(\mathrm{n}=11)$, passive-vehicle $(\mathrm{n}=10)$ and passive-antalarmin $(\mathrm{n}=10)$. b mRNA expression of CRH and CRH-R1 in the hypothalamus of the different groups analyzed on day 24 following defeat: manipulated control-vehicle $(\mathrm{n}=8)$, manipulated control-antalarmin $(\mathrm{n}=8)$, active-vehicle $(\mathrm{n}=11)$, active-antalarmin $(\mathrm{n}=11)$, passivevehicle $(n=10)$ and passive-antalarmin $(n=10)$. c mRNA expression of CRH in the amygdala of the different groups analyzed on day 24 following defeat: manipulated control-vehicle $(n=8)$, manipulated control-antalarmin $(\mathrm{n}=8)$, active-vehicle $(\mathrm{n}=11)$, active-antalarmin $(n=11)$, passive-vehicle $(n=10)$ and passive-antalarmin $(n=10)$. Data are expressed as means \pm SEM. ${ }^{*} \mathrm{p}<0.05$ (Tukey's tests). 


\section{Discussion}

The results obtained in this study reveal that chronic social stress triggers two different dynamic responses in both the HPA and SAM axes that are associated with behavioral coping strategies. This finding supports the existence of two different behavioral profiles in response to chronic defeat that are associated with different physiological characteristics $[2,4,5]$. After 18 days of defeat, the subjects with a passive behavioral profile differed from their active counterparts mainly by the immobility behavior and social and nonsocial exploration. On day 21, the passive subjects had increased immobility and lower social and nonsocial exploration than the active subjects. The passive subjects also had reduced nonsocial exploration between days 18 and 21 .

According to previous studies [5], the passive subjects had a hypersecretion of corticosterone in response to stress on day 21 and lower resting plasma corticosterone levels than the manipulated controls on day 24 prior to defeat. A reduction was also apparent compared to basal levels on day 0. Contrary to initial expectations [40], the pharmacological treatment with antalarmin, which blocks CRH receptors, failed to have any effect on either the HPA axis or social behavior in any of the variables measured. Other studies focusing on chronic stress have also found hypocortisolism in resting conditions and hypersecretion of corticosterone in response to stress in animals [41]. In humans, hypocortisolemia has been associated with periods of prolonged stress $[20,21]$ and atypical depression and PTSD, among other pathologies $[8,21,42,43]$, with excessive cortisol secretion in response to stress in PTSD [42, 44]. However, the pathway by which this pattern of altered activity is activated is unclear.

One possible mechanism may be a deregulation of the $\mathrm{CRH}$ pathways, which could also be responsible for the lack of effects from antalarmin treatment. The higher hypothalamic resting expression levels of CRH in the passive subjects in comparison to the active subjects on day 23 did not correlate with the low corticosterone levels found in the passive subjects and the upregulation of hypothalamic glucocorticoid receptors found previously [5]. Although other possibilities exist, this apparent discrepancy may be explained by the downregulation of $\mathrm{CRH}$ receptors in the pituitary gland, which is associated with high CRH levels as a result of stress-induced hyperactivity of the axis, which would be indicated by the high corticosterone levels 21 days after defeat $[45,46]$. This mechanism has also been proposed in patients with PTSD $[42,47]$, which is characterized by hypersecretion of CRH
$[11,48]$, lower basal cortisol levels [42] and high levels of the glucocorticoid receptor [49]. Although some authors have not reported these results [50], other authors have found an increase in basal CRH mRNA expression and $\mathrm{CRH}$ biosynthesis in animals submitted to repeated immobilization stress and adrenalectomized rats [51]. Thus, it has been suggested that hypothalamic CRH neurons respond to repeated stimulation in a glucocorticoid-independent manner [52]. However, these differences may be due to procedural differences, such as the duration of stress and the time that the variables are measured. Other structures, such as the amygdala, modulate the HPA axis response, but no differences in the resting expression levels of CRH were found in the amygdala or the hypothalamic receptors on day 23 , indicating that the changes observed in the HPA axis are not mediated by the CRH afferents from the amygdala.

The low resting corticosterone levels found in the passive subjects may reflect the inability of the HPA axis to respond to stress. However, following a new defeat on day 24 , both the passive and active subjects had an increased corticosterone response compared to the manipulated controls. Nevertheless, the corticosterone levels found in the passive subjects and manipulated controls were lower than those found in these same groups on day 21. In the nonstressed subjects, this may be attributed to the passage of time. Although there is evidence for reduced HPA responses after chronic stress [53], the reduction observed in the passive subjects can be attributed to the stress-induced effect specific to this group because the changes in question were not observed in the active subjects. This gradual blunting of the HPA axis response in the passive subjects is supported by the fact that both the active and passive subjects have the same CRH expression levels in the hypothalamus on day 24 following the final defeat. Furthermore, this increase in CRH expression could explain the downregulation of hypothalamic CRH-R1 receptors found in all of the stressed subjects at this time. This agrees with other studies that also found that chronic stress and elevated corticosterone reduce the levels of $\mathrm{CRH}-\mathrm{R} 1$ receptors and mRNA in the paraventricular nucleus of the hypothalamus [54]. Despite the limitations imposed by the fact that protein levels were not measured, the increased $\mathrm{CRH}$ expression levels in the amygdala from the passive subjects after defeat could indicate greater activity taking place in this structure, which in turn may influence behavior, as shown in the increased immobility during the FST in the passive subjects compared to their active counterparts (fig. 2). Other studies found that intracerebroventricular administration of $\mathrm{CRH}$ triggered
Pérez-Tejada/Arregi/Gómez-Lázaro/ Vegas/Azpiroz/Garmendia 
an increase in immobility in the FST after chronic stress [55].

Contrary to the initial expectations and data reported in the literature [3,24], the stressed subjects did not show elevated catecholamine levels compared to the nonstressed subjects. Even on day 24 after defeat, the passive subjects had lower noradrenaline levels than the manipulated controls and lower adrenaline levels than the active subjects. Thus, a general reduction in the passive subjects occurred. It is known that CRH activates the SAM axis, resulting in increased catecholamine levels in the plasma [56]. This study reported an increase in hypothalamic $\mathrm{CRH}$ expression levels in the passive subjects in resting conditions and, on day 24 after defeat, an increase in both groups. These results suggest that the observed decrease in catecholamine levels in the passive subjects is not directly mediated by CRH [57].

It should be noted that the noradrenaline and adrenaline levels were measured after the maximum catecholamine peak in response to stress. Therefore, the plasma levels do not reflect the immediate stress response, but rather the subsequent changes that may occur later. Nevertheless, it has been suggested that the increase in catecholamine synthesis enzymes induced by the repeated stress experiences is maintained for prolonged periods of time even after the cessation of the stressor itself, providing a 'memory' of said experience [58]. Thus, in this study, differences in the activity of the catecholamine enzymes correlated with the strategy on day 24 following the defeat. The lower levels of $\mathrm{DBH}, \mathrm{TH}$ expression and adrenaline in the passive subjects compared to the active subjects, and the low levels of noradrenaline in the passive subjects compared to the manipulated controls may be indicative of a tendency of this group to present lower SAM axis activity. Lower plasma DBH activity has been reported in different psychopathological disorders [59]. Although evidence suggests a hyperactive SAM system in patients with PTSD [60-63], Mustapic et al. [64] reported lower DBH activity in war veterans with PTSD compared to war veterans without PTSD, indicating that those who exhibited lower plasma DBH activity after a traumatic event were less resilient and more vulnerable to developing PTSD. This finding is consistent with the decrease in catecholamine levels observed on day 24 in the passive subjects. Furthermore, on day 23, differences were observed in $\mathrm{DBH}$ and $\mathrm{TH}$ resting expression, with the active subjects having higher expression levels than the manipulated controls. This finding suggests a greater activity of the SAM axis in the active subjects as a result of the previous stress response, which is maintained over time. This greater activity may also lead to negative consequences for the organism [3]. At this time, all of the antalarmintreated subjects had reduced resting levels of plasma catecholamines, but not $\mathrm{TH}$ and $\mathrm{DBH}$, suggesting that the treatment could affect the plasma catecholamine release only out of a challenge context.

Social stress had an anhedonic effect, which manifested in an increased latency to ingest a novel but palatable food, as well as an increased swimming latency in the FST observed in all stressed mice, indicating that chronic defeat triggers behavioral changes that relate to depression. Our data also agree with other studies that have reported subjects exposed to chronic defeat exhibit an anhedoniclike response in the NPT [34], suggesting that social stress experienced chronically can affect an animal's motivation and lead to the development of hedonic and motivational deficits [65]. Although the data reveal no differences in the NPT or swimming latency in the FST as a function of strategy adopted by the subjects, there were differences in immobility in the FST between the two groups; the passive subjects displayed greater levels of immobility compared to their active counterparts, but not with the manipulated controls. This observation may indicate that a passive coping strategy can be more susceptible than an active strategy to the behavioral effects of social stress. Other authors have also observed an increase in the immobility of passive subjects exposed to chronic defeat [5] and mice genetically selected for long attack latency [4].

Hyperactivity of the CRH-R1 pathways has been associated with disorders such as depression [11], which provides a rationale for using CRH-R1 antagonists as a treatment. Specifically, these antagonists have been effective in treating hyperactivity associated with high corticosterone levels [66] as observed in melancholic depression $[8,9]$. Our data reveal that the physiological profile found in the stressed subjects does not contain high resting levels of corticosterone or CRH mRNA compared to the controls, and indeed, in the passive subjects, corticosterone levels are clearly diminished. Moreover, it has been reported that passive subjects have high glucocorticoid receptor levels in the hypothalamus following 21 days of chronic defeat [5], and it is known that CRH-R1 antagonists trigger an increase in these receptors [67]. Therefore, this may explain why treatment with antalarmin for 6 days failed to produce any changes in the HPA axis.

It has been reported that treatment with antalarmin blocks the response to acute stress [68], which prevents the deleterious effects of the increase in glucocorticoids and may prevent disorders such as PTSD [69]. However, controversy also exists regarding the effectiveness of 
CRH-R1 antagonists because several animal studies failed to report a blunted HPA axis response to chronic social stress as a result of treatment [70]. These data, along with the results in this study, suggest that chronic social stress triggers changes in the HPA axis as the stress is prolonged that may prevent the effects of $\mathrm{CRH}$ receptor antagonists that have been observed in other studies of acute stress [40]. It is possible that the administration of antalarmin before or at the beginning of stress can prevent the effects of chronic stress, and longer treatment may be necessary to reverse the changes already produced.

We conclude that following a prolonged period of social stress, differences are observed in relation to dynamic changes in the HPA and SAM axes that are associated with the adopted behavioral strategy. The active coping profile results in an HPA axis response that remains the same over time. The active subjects also showed a greater degree of SAM axis activity manifested by an increase in catecholamine synthesis enzymes and higher plasma adrenaline levels when compared with the passive subjects on day 24 . The profile of physiological changes found in the passive subjects, including changes in the HPA and SAM axes, along with the high levels of glucocorticoid receptor expression found in previous studies, may be associated with changes related to mood disorders, such as PTSD and depression. Both physiological profiles affect behavior; there was an increase in latency for both ingestion in the NPT and swimming in the FST. Nevertheless, the fact that the passive subjects also exhibit increased immobility in the FST compared to their active counterparts may be indicative of a greater degree of vulnerability of these subjects to the effects of stress. The pharmacological treatment with antalarmin failed to reverse the effects of stress. This failure may be because the profile of changes in the $\mathrm{CRH}$ pathway in response to chronic social stress does not cor- respond to the physiological profile for which this drug seems to be most effective. A more prolonged treatment may also have been necessary.

This study shows the importance of the time course of these physiological changes, which depend on the duration of stress and the coping strategy adopted, and which may respond selectively to different treatments, thus improving our understanding of the relationship between stress and the development of psychopathologies. It is also worth highlighting the ethological validity of the procedure used to establish the coping strategies since the whole behavioral repertoire manifested by subjects in situations of defeat was analyzed. This study is unique in that it uses prolonged defeat-induced stress to establish different behavioral strategies (through the aforementioned procedure) and to analyze the changes triggered at different moments in the activity of the HPA and SAM axes, as well as in the central structures related to both systems. It is also unique in that it analyzes the effects of treatment with a CRH-R1 antagonist in this situation.

\section{Acknowledgements}

The technical and human support provided by SGIker (UPV/ EHU, MICINN, GV/EJ, ESF) are gratefully acknowledged. This study was supported by the Predoctoral Fellowship of the Spanish Ministry of Science and Education BES-2009-017586, the project grants of the Spanish Ministry of Science and Innovation PSI2008囚00161/PSIC and the Basque Government GIC07/19-238 project grants.

\section{Disclosure Statement}

All authors declare that they have no conflicts of interest.

\section{References}

1 Cryan JF, Slattery DA: Animal models of mood disorders: recent developments. Curr Opin Psychiatry 2007;20:1-7.

2 Walker FR, Masters LM, Dielenberg RA, Day TA: Coping with defeat: acute glucocorticoid and forebrain responses to social defeat vary with defeat episode behavior. Neuroscience 2009; 162:244-253.

-3 Koolhaas JM, Korte SM, De Boer SF, Van Der Vegt BJ, Van Reenen CG, Hopster H, De Jong IC, Ruis MAW, Blokhuis HJ: Coping styles in animals: current status in behavior and stressphysiology. Neurosci Biobehav Rev 1999;23: 925-935.
4 Veenema AH, Meijer OC, de Kloet ER, Koolhaas JM, Bohus BG: Differences in basal and stress-induced HPA regulation of wild house mice selected for high and low aggression. Horm Behav 2003;43:197-204.

5 Gomez-Lazaro E, Garmendia L, Beitia G, Perez-Tejada J, Azpiroz A, Arregi A: Effects of a putative antidepressant with a rapid onset of action in defeated mice with different coping strategies. Prog Neuropsychopharmacol Biol Psychiatry 2012;38:317-327.

-6 De Miguel Z, Vegas O, Garmendia L, Arregi A, Beitia G, Azpiroz A: Behavioral coping strategies in response to social stress are as- sociated with distinct neuroendocrine, monoaminergic and immune response profiles in mice. Behav Brain Res 2011;225:554-561.

7 Touma C, Bunck M, Glasl L, Nussbaumer M, Palme R, Stein H, Wolferstätter M, Zeh R, Zimbelmann M, Holsboer F, Landgraf R: Mice selected for high versus low stress reactivity: a new animal model for affective disorders. Psychoneuroendocrinology 2008;33:839-862.

8 Gold PW, Chrousos GP: Organization of the stress system and its dysregulation in melancholic and atypical depression: high vs low CRH/NE states. Mol Psychiatr 2002;7:254275 . 
9 de Kloet ER, Joels M, Holsboer F: Stress and the brain: from adaptation to disease. Nat Rev Neurosci 2005;6:463-475.

10 Nemeroff CB, Bremner JD, Foa EB, Mayberg HS, North CS, Stein MB: Posttraumatic stress disorder: a state-of-the-science review. J Psychiatr Res 2006;40:1-21.

$\rightarrow 11$ Kehne JH: The CRF1 receptor, a novel target for the treatment of depression, anxiety, and stress-related disorders. CNS Neurol Disord Drug Targets 2007;6:163-182.

-12 Kasckow JW, Baker D, Geracioti TD: Corticotropin-releasing hormone in depression and post-traumatic stress disorder. Peptides 2001 22:845-851.

13 Yehuda R, Southwick SM, Nussbaum G, Wahby V, Giller EL, Mason JW: Low urinary cortisol excretion in patients with posttraumatic stress disorder. J Nerv Ment Dis 1990; 178:366-369.

14 Miczek KA: New test for aggression in rats without aversive stimulation: differential effects of d-amphetamine and cocaine. Psychopharmacology (Berl) 1979;60:253-259.

$\checkmark 15$ Zoladz PR, Fleshner M, Diamond DM: Psychosocial animal model of PTSD produces a long-lasting traumatic memory, an increase in general anxiety and PTSD-like glucocorticoid abnormalities. Psychoneuroendocrinology 2012;37:1531-1545.

-16 Müller MB, Holsboer F: Mice with mutations in the HPA-system as models for symptoms of depression. Biol Psychiatry 2006;59:11041115.

17 Koolhaas J, Bohus B: Animal models of stress and immunity; in Leonard B, Miller K (eds): Stress, the Immune System and Psychiatry. New York, Wiley and Sons, 1995.

-18 Kudryavtseva NN, Bakshtanovskaya IV, Koryakina LA: Social model of depression in mice of C57BL/6J strain. Pharmacol Biochem Behav 1991;38:315-320.

19 Gomez-Lazaro E, Arregi A, Beitia G, Vegas O, Azpiroz A, Garmendia L: Individual differences in chronically defeated male mice: behavioral, endocrine, immune, and neurotrophic changes as markers of vulnerability to the effects of stress. Stress 2011;14:537548.

20 Hellhammer DH, Wade S: Endocrine correlates of stress vulnerability. Psychother Psychosom 1993;60:8-17.

-21 Fries E, Hesse J, Hellhammer J, Hellhammer DH: A new view on hypocortisolism. Psychoneuroendocrinology 2005;30:1010-1016.

22 Uschold-Schmidt N, Nyuyki KD, Füchsl AM, Neumann ID, Reber SO: Chronic psychosocial stress results in sensitization of the HPA axis to acute heterotypic stressors despite a reduction of adrenal in vitro ACTH responsiveness. Psychoneuroendocrinology 2012;10 1676-1687.

-23 Flandreau EI, Ressler KJ, Owens MJ, Nemeroff CB: Chronic overexpression of corticotropinreleasing factor from the central amygdala produces HPA axis hyperactivity and behavioral anxiety associated with gene-expression changes in the hippocampus and paraventricular nucleus of the hypothalamus. Psychoneuroendocrinology 2012;37:27-38.

24 Sgoifo A, De Boer SF, Haller J, Koolhaas JM: Individual differences in plasma catecholamine and corticosterone stress responses of wild-type rats: relationship with aggression. Physiol Behav 1996;60:1403-1407.

25 Agelink MW, Boz C, Ullrich H, Andrich J: Relationship between major depression and heart rate variability. Clinical consequences and implications for antidepressive treatment. Psychiatry Res 2002;113:139-149.

26 Liberzon I, Taylor SF, Amdur R, Jung TD, Chamberlain KR, Minoshima S, Koeppe RA, Fig LM: Brain activation in PTSD in response to trauma-related stimuli. Biol Psychiatry 1999;45:817-826

27 Grigoriadis DE: The corticotropin-releasing factor receptor: a novel target for the treatment of depression and anxiety-related disorders. Expert Opin Ther Targets 2005;9:651-684.

28 Gutman DA, Owens MJ, Thrivikraman KV Nemeroff CB: Persistent anxiolytic affects after chronic administration of the CRF1 receptor antagonist R121919 in rats. Neuropharmacology 2011;60:1135-1141.

29 Golde WT, Gollobin P, Rodriguez LL: A rap id, simple, and humane method for submandibular bleeding of mice using a lancet. Lab Anim (NY) 2005;34:39-43.

30 Paxinos G, Franklin KBJ: The Mouse Brain in Stereotaxic Coordinates. San Diego, Academic Press, 2001.

31 Kudryatseva NN: Sensory contact model: protocol, control, applications. Nature Precedings 2009. http://hdl.handle.net/10101/ npre.2009.3299.1.

32 Brain PF, McAllister KH, Walmsley S: Drug effects on social behavior: methods in ethopharmacology; in Boulton AA, Baker GB Greenshaw AJ (eds): Neuromethods. Totowa, Humana Press, 1989, pp 687-739.

33 Merali Z, Levac C, Anisman H: Validation of a simple, ethologically relevant paradigm for assessing anxiety in mice. Biol Psychiat 2003; 54:552-565.

34 Dadomo H, Sanghez V, Di Cristo L, Lori A, Ceresini G, Malinge I, Parmigiani S, Palanza P, Sheardown M, Bartolomucci A: Vulnerability to chronic subordination stress-induced depression-like disorders in adult $129 \mathrm{SvEv}$ male mice. Prog Neuropsychopharmacol Biol Psychiatry 2011;35:1461-1471.

35 Cryan JF, Holmes A: The ascent of mouse: advances in modelling human depression and anxiety. Nat Rev Drug Discov 2005;4:775790.

36 Zorrilla EP, Valdez GR, Nozulak J, Koob GF, Markou A: Effects of antalarmin, a CRF type 1 receptor antagonist, on anxiety-like behavior and motor activation in the rat. Brain Res 2002;952:188-199.

37 Ducottet C, Griebel G, Belzung C: Effects of the selective nonpeptide corticotropin-releasing factor receptor 1 antagonist antalarmin in the chronic mild stress model of depression in mice. Prog Neuropsychopharmacol Biol Psychiatry 2003;27:625-631.

38 Chomczynski P, Sacchi N: Single-step method of RNA isolation by acid guanidinium thiocyanate-phenol-chloroform extraction. Anal Biochem 1987;162:156-159.

-39 Livak KJ, Schmittgen TD: Analysis of relative gene expression data using real-time quantitative PCR and the 2(-Delta Delta C(T)) Method. Methods 2001;25:402-408

40 Habib KE, Weld KP, Rice KC, Pushkas J, Champoux M, Listwak S, Webster EL, Atkinson AJ, Schulkin J, Contoreggi C, Chrousos GP, McCann SM, Suomi SJ, Higley JD, Gold PW: Oral administration of a corticotropinreleasing hormone receptor antagonist significantly attenuates behavioral, neuroendocrine, and autonomic responses to stress in primates. Proc Natl Acad Sci USA 2000;97: 6079-6084.

41 Bowens N, Heydendael W, Bhatnagar S, Jacobson L: Lack of elevations in glucocorticoids correlates with dysphoria-like behavior after repeated social defeat. Physiol Behav 2012;105:958-965.

42 Yehuda R: Neuroendocrine aspects of PTSD. Handb Exp Pharmacol 2005;169:371-403.

43 Antonijevic IA: Depressive disorders - is it time to endorse different pathophysiologies? Psychoneuroendocrinology 2006;31:1-15.

-44 Elzinga BM, Schmahl CG, Vermetten E, van Dyck R, Bremner JD: Higher cortisol levels following exposure to traumatic reminders in abuse-related PTSD. Neuropsychopharmacology 2003;28:1656-1665.

-45 Hauger RL, Millan MA, Lorang M, Harwood JP, Aguilera G: Corticotropin-releasing factor receptor and pituitary-adrenal responses during immobilization stress. Endocrinology 1988;123:396-405.

46 Houshyar H, Galigniana MD, Pratt WB, Woods JH: Differential responsivity of the hypothalamic-pituitary-adrenal axis to glucocorticoid negative-feedback and corticotropin releasing hormone in rats undergoing morphine withdrawal: possible mechanisms involved in facilitated and attenuated stress responses. J Neuroendocrinol 2001;13:875886

47 Baker DG, West SA, Nicholson WE, Ekhator NN, Kasckow JW, Hill KK, Bruce AB, Orth DN, Geracioti TD Jr: Serial CSF corticotropin-releasing hormone levels and adrenocortical activity in combat veterans with posttraumatic stress disorder. Am J Psychiatry 1999;156:585-588.

48 Bremner JD, Licinio J, Darnell A, Krystal JH, Owens MJ, Southwick SM, Nemeroff CB, Charney DS: Elevated CSF corticotropin-releasing factor concentrations in posttraumatic stress disorder. Am J Psychiatry 1997;154: 624-629.

49 Yehuda R, Southwick SM, Krystal JH, Bremner D, Charney DS, Mason JW: Enhanced suppression of cortisol following dexamethasone administration in posttraumatic stress disorder. Am J Psychiatry 1993;150:83-86. 
50 Wood SK, Walker HE, Valentino RJ, Bhatnagar S: Individual differences in reactivity to social stress predict susceptibility and resilience to a depressive phenotype: role of corticotropin-releasing factor. Endocrinology 2010;151:1795-1805.

-51 Marti O, Harbuz MS, Andres R, Lightman SL, Armario A: Activation of the hypothalamicpituitary axis in adrenalectomised rats: potentiation by chronic stress. Brain Res 1999;821: $1-7$.

52 Santibanez M, Gysling K, Forray MI: Desipramine prevents the sustained increase in corticotropin-releasing hormone-like immunoreactivity induced by repeated immobilization stress in the rat central extended amygdala. J Neurosci Res 2006;84:1270-1281.

53 Heim C, Ehlert U, Hellhammer DH: The potential role of hypocortisolism in the pathophysiology of stress-related bodily disorders. Psychoneuroendocrinology 2000;25:1-35.

54 Bonaz B, Rivest S: Effect of a chronic stress on CRF neuronal activity and expression of its type 1 receptor in the rat brain. Am J Physiol 1998;275:1438-1449.

55 Swiergiel AH, Zhou Y, Dunn AJ: Effects of chronic footshock, restraint and corticotropin-releasing factor on freezing, ultrasonic vocalization and forced swim behavior in rats. Behav Brain Res 2007;183:178-187.

-56 Irwin M, Hauger R, Brown M: Central corticotropin-releasing hormone activates the sympathetic nervous system and reduces immune function: increased responsivity of the aged rat. Endocrinology 1992;131:10471053.
57 Murphy EK, Sved AF, Finlay JM: Corticotropinreleasing hormone receptor blockade fails to alter stress-evoked catecholamine release in prefrontal cortex of control or chronically stressed rats. Neuroscience 2003;116:1081-1087.

58 Sabban EL: Catecholamine and stress; in Soreq H, Friedman A, Kaufer D (eds): Stress From Molecules to Behavior: A Comprehensive Analysis of the Neurobiology of Stress Responses. Weinheim, Wiley, 2010, pp 19-35.

59 Cubells JF, Zabetian CP: Human genetics of plasma dopamine beta-hydroxylase activity: applications to research in psychiatry and neurology. Psychopharmacology (Berl) 2004; 174:463-476.

60 Young EA, Breslau N: Cortisol and catecholamines in posttraumatic stress disorder: an epidemiologic community study. Arch Gen Psychiatry 2004;61:394-401.

61 Geracioti TD, Baker DG, Ekhator NN, West SA, Hill KK, Bruce AB, Schmidt D, RoundsKugler B, Yehuda R, Keck PE, Kasckow JW: CSF norepinephrine concentrations in posttraumatic stress disorder. Am J Psychiatry 2001;158:1227-1230.

62 Hawk LW, Dougall AL, Ursano RJ, Baum A: Urinary catecholamines and cortisol in recent-onset posttraumatic stress disorder after motor vehicle accidents. Psychosom Med 2000;62:423-434.

63 Yehuda R, Southwick S, Giller EL, Ma X, Mason JW: Urinary catecholamine excretion and severity of PTSD symptoms in Vietnam combat veterans. J Nerv Ment Dis 1992;180:321-325.

64 Mustapic M, Pivac N, Kozaric-Kovacic D, Dezeljin M, Cubells JF, Muck-Seler D: Dopamine beta-hydroxylase (DBH) activity and $-1021 \mathrm{C} / \mathrm{T}$ polymorphism of $\mathrm{DBH}$ gene in combat-related post-traumatic stress disorder. Am J Med Genet B Neuropsychiatr Genet $2007 ; 144: 1087-1089$.
65 Rygula R, Abumaria N, Flügge G, Fuchs E, Rüther E, Havemann-Reinecke U: Anhedonia and motivational deficits in rats: impact of chronic social stress. Behav Brain Res 2005; 162:127-134.

66 Erhardt A, Müller MB, Rodel A, Welt T, Ohl F, Holsboer F, Keck ME: Consequences of chronic social stress on behavior and vasopressin gene expression in the PVN of DBA/2OlaHsd mice - influence of treatment with the CRHR1antagonist R121919/NBI 30775. J Psychopharmacol 2009;23:31-39.

67 Post A, Ohl F, Almeida OF, Binder EB, Rücker M, Welt S, Binder E, Holsboer F, Sillaber I: Identification of molecules potentially involved in mediating the in vivo actions of the corticotropin-releasing hormone receptor 1 antagonist, NBI30775 (R121919). Psychopharmacology (Berl) 2005;180:150-158.

68 Vegas O, Garmendia L, Arregi A, Beitia G, Azpiroz A: Effects of antalarmin and nadolol on the relationship between social stress and pulmonary metastasis development in male OF1 mice. Behav Brain Res 2009;205:200-206.

69 Zoumakis E, Rice KC, Gold PW, Chrousos GP: Potential uses of corticotropin-releasing hormone antagonists. Ann NY Acad Sci 2006; 1083:239-251.

70 Ayala AR, Pushkas J, Higley JD, Ronsaville D, Gold PW, Chrousos GP, Pacak K, Calis KA, Gerald M, Lindell S, Rice KC, Cizza G: Behavioral, adrenal, and sympathetic responses to long-term administration of an oral corticotropin-releasing hormone receptor antagonist in a primate stress paradigm. J Clin Endocrinol Metab 2004;89:5729-5737. 